\title{
The development of an information systems strategic plan: an e-government perspective
}

\author{
Sitalakshmi Venkatraman* \\ School of Information Technology \\ and Mathematical Sciences \\ University of Ballarat \\ P.O. Box 663, Ballarat, Victoria 3353, Australia \\ E-mail: s.venkatraman@ballarat.edu.au \\ *Corresponding author
}

\section{Stephen Hughes}

\author{
New Zealand Ministry \\ P.O. Box 180 \\ Wellington 6001, New Zealand \\ E-mail: ctek@xtra.co.nz
}

\begin{abstract}
Information and Communications Technologies (ICTs) have been playing a major role in governments across the world to improve the efficiency, effectiveness and quality of public services. However, ICT has been utilised only in a piecemeal fashion by different public sectors and, hence, many governments are keen to incorporate an integrated e-government strategy to achieve business and service excellence.

This paper presents the development of an Information Systems Strategic Plan (ISSP) for a large government organisation as a case study. We discuss the evolution of an e-government strategy and examine its influence in the development of an information systems strategy within a state sector organisation in New Zealand. The findings from the case study analysis are used to measure the degree of alignment between the objectives of the e-government strategy and the organisation's ISSP strategy. We identify the challenges that face the organisation and propose a ten-point framework for the improvement of the ISSP alignment with the e-government strategy. Finally, we conclude with a summary of the outcomes of this study and the future research directions.
\end{abstract}

Keywords: e-government; information systems; Information Systems Strategic Plan; alignment.

Reference to this paper should be made as follows: Venkatraman, S. and Hughes, S. (2009) 'The development of an information systems strategic plan: an e-government perspective', Int. J. Business Excellence, Vol. 2, No. 1, pp.50-64.

Biographical notes: Dr. Sitalakshmi Venkatraman is a Senior Lecturer in the School of Information Technology and Mathematical Sciences at the University of Ballarat, Australia. She has 20 years of work experience in industry, developing turnkey IT projects and in academics, teaching a variety of computing courses. She has published a variety of research papers, both technology-based and management-oriented, in internationally well-known 
refereed journals that focus on topics such as efficient algorithms, technology adoption, mobile computing, service quality and project management. Her current research interests are in the Information Systems (ISs) management and e-commerce domains.

\begin{abstract}
Stephen Hughes is an independent Consultant currently working in the Ministry of New Zealand. He is an experienced IT professional, having worked in IT for over 16 years, where his roles have included managing teams of project managers and IT consultants. He has undertaken several IT programmes and project management assignments across a range of commercial and government clients. He has recently completed his Masters degree in Information Management at Victoria University, Wellington, New Zealand, where his areas of interest and research include IT outsourcing, IT project management and ISSP development.
\end{abstract}

\title{
1 Introduction
}

Recent developments in the Information and Communications Technologies (ICTs) have lead to the evolution of e-government strategies (Siau and Long, 2005; Germanakos et al., 2006). Many countries have started to realise that there is an unlimited potential for online services to be tapped more effectively and efficiently to improve their government services across various departments and agencies (Kaylor et al., 2001; European Commission, 2004; Millar, 2004; Ke and Kee, 2004; Basu, 2004; De, 2005; Obi, 2007). Such a strategy, termed as e-government is a key consideration for public sector organisations undertaking information systems planning as it provides an important external input into the development process of an Information Systems Strategic Plan (ISSP).

Schware and Sudan (2005) describe many definitions of the term 'e-government', such as, 'the transformation of public sector internal and external relationships through net enabled operations and information and communications technology to optimise government service delivery, constituency participation and internal government operations'. Central to such definitions of e-government is the concept of being able to transform government services towards achieving business and service excellence through the use of ICT (As-Saber et al., 2006). E-government is potentially aimed at offering compelling benefits, including better-quality government services, enhanced efficiency and reduced costs (Germanakos et al., 2006; Poelmans, 2006). However, most countries have not been quite successful in achieving the expected benefits through e-government initiatives and the results have been disappointing (Gichoya, 2005; Andersen, 2006; Poelmans, 2007; Lee et al., 2008). This warrants a research study to understand the various challenges surrounding e-government implementations and their impact on the business strategies. This paper attempts to unearth such issues through a case study conducted in one of the government agencies in New Zealand.

One of the core themes of New Zealand's latest e-government strategy is to build upon the increased use of networking technologies and seize the opportunities that ICT offers so as to transform the way government works while delivering services, providing information, and interacting with people (NZSSC, 2003). Through a case study that analyses the development of an ISSP, we examine to what extent the e-government 
strategy is influencing the development of the information systems strategy within one of New Zealand's government agencies. We analyse the challenges government agencies face in aligning their individual IT strategies with the e-government strategy. Based on the findings from the case study analysis, we propose a framework for achieving greater alignment between the e-government strategies and individual strategies of government agencies.

The structure of the paper is as follows. We present the research methodology undertaken in Section 2 and then in Section 3 we describe the ISSP development process of the case study. Section 4 provides a summary of the findings from the case study analysis and in Section 5 we propose a framework for improving the alignment between the objectives of an ISSP development and e-government strategy. Finally, Section 6 presents the conclusions and suggestions for future research.

\section{Research background}

\subsection{Literature Review}

As the basis for the theoretical framework of this study, we analysed some of the researchers' theoretical ramifications made in the past decade from literature on ISSP development. These include the work by Byrd et al. (1995), who studied IT planning in large, public sector organisations and proposed a number of conditions that affect the quality of the ISSP process. They opine that the agency size, maturity of infrastructure, use of external consultants, and top management support are some of the influencing factors for the successful development of an ISSP. On the other hand, Ang and Teo (2001) identified a number of major IS planning problems associated with developing information systems plans and cite key factors such as, failure to secure top management support, poor communication flow, and failure to secure sufficiently qualified personnel that could affect the outcome of an ISSP process. Some researchers (Chan and Huff, 1993) have considered approaches for measuring information systems planning effectiveness. The use of key themes to show the potential benefits of IT and with themes broken down into identifiable and frequent deliverables could contribute to ISSP success (Earl, 1993).

We also studied the strategic alignment models from literature as the basis for conducting the case study analysis. Henderson and Venkatraman (1993) provide a framework for organisations to harness the potential benefits of IT with the key concept of achieving a balance between strategic fit and functional integration. Other researchers (Lederer and Sethi, 1996; Mentzas, 1997) have also emphasised linkage of IS strategy with corporate strategy for realising the potential benefits of an ISSP. Some recent work (Chan et al., 2006; Teubner, 2007; Tallon, 2008) provide insights into what constitutes a successful business and IT alignment across different organisational types.

Regarding e-government strategies, we studied the global situation pertaining to e-government trends in both developed and developing countries (Kaylor et al., 2001; Schware and Sudan, 2005; Griffin and Halpin, 2005; Wimmer et al., 2007; Krishna and Walsham, 2005; Andersen, 2006; Dillon et al., 2006; Wang et al., 2007; Lee et al., 2008). In particular, we gathered information relating to New Zealand's e-government 
strategies from published documents of the State Services Commission (NZSSC, 2003). The work by Millar (2004) provides a rich source of information pertaining to the development of e-government strategies in New Zealand.

\subsection{Research methodology}

From the literature review, we opine that, in order to develop an ISSP to successfully align with e-government and business strategies, issues pertaining to IS architectures, interoperability frameworks, organisational structures and shared services are to be explored and these could vary from one organisation to another. Hence, a case-based approach was adopted as the research methodology to examine the development process of an ISSP and its influence on achieving the e-government and business strategies. One of the government agencies of the state services commission of New Zealand was considered for the case study (referred to as the Agency hereafter) as it was initiating a new ISSP development process. The focus of the case study was primarily on the development of the Agency's ISSP with respect to examining the effectiveness of the methodology used, and assessing the extent to which the ISSP had achieved alignment with the Agency's business strategies and the New Zealand Government's e-government strategies. We also examined to what extent New Zealand's e-government strategy had influenced the development of the information systems strategy within the organisation. Information relating to the case was collected by conducting semi-structured interviews with the Agency staff involved in the development of the ISSP.

We designed a questionnaire to assess the success of the ISSP through investigating the following three main aspects:

1 the ISSP development process and methodology

2 the alignment achieved by the ISSP with the organisation's business strategy

3 the alignment achieved by the ISSP with the e-government initiatives.

Each interviewee was asked a series of 24 semi-structured questions that were qualitative in nature. A limited quantitative-type question and analysis was also undertaken as part of the interview whereby interviewees were asked to rate the various aspects of the ISSP on a scale of 1 to 5 ( 1 being 'failure' and 5 being 'highly successful'). We examined the success of the ISSP by evaluating the success factors of the ISSP development process and the methodology adopted, and the degree of alignment of the ISSP with the business strategies as well as with e-government initiatives.

Data gathered from the interview process was consolidated to produce the main findings of the case study. These were verified by accessing the project documentation that was produced as part of the Agency's ISSP development project. Data on the e-government strategies and initiatives was also gathered from publicly available information published on the New Zealand Government websites and from other related international community. 


\section{Development of an ISSP - a case study}

\subsection{Case study background}

The e-government strategy of New Zealand identifies three broad characteristics, namely, convenience and satisfaction, integration and efficiency, and trust and participation. This has been translated to the e-government vision statement as, 'a methodical, graduated approach, cross-government collaboration, a commitment to using ICT in ways that would increase rather than limit opportunities for participation, and a determination to ensure that the technology was only an instrument for an improved public sector, not an end in itself' (Millar, 2004). Following the government's adoption of the vision statement, an E-government Unit was formally established in the State Services Commission of New Zealand in July 2000.

The main objective of the E-government Unit is the alignment of the e-government initiatives with the six development goals of the state service as the basis upon which the e-government themes and work programmes are being developed. These six development goals are:

1 employer of choice

2 excellent state servants

3 coordinated state agencies

4 networked state services

5 accessible state services

6 trusted state services.

In 2003, a couple of departments were merged to form a new government agency with the view of integrating their operations. The new Agency was driven by renewed expectations in terms of the quality of overall service delivery, effective leadership and strengthened connections between policy development and its operational implementation. The key stakeholders served by the Agency are the Agency user community (including external partners), the experts, and the public. A review undertaken as part of the merger planning and preparation activities was the "merger situation analysis'. This review provided a high level analysis of the nature and state of information management and information technology at the former departments. One of the key findings from the Merger Situation Analysis report was that much of the IT infrastructure was in an unsatisfactory state and needed immediate attention. The report noted that stabilising the infrastructure required to be upgraded as an immediate priority for the Agency and, as a result, the 'infrastructure upgrade programme' was established.

Subsequently, in 2004, the Agency's IT environment was one of the key focus areas and the findings of a 'baseline review' indicated that the Agency's IT capability was at a very early stage of maturity when compared with international benchmarks and that the previous departments' lack of investment and expertise was causing a significant risk to the ongoing delivery of business in terms of systems stability and security. Hence, this became the main focus for the new IT department. The baseline review recommended the formulation of a new ISSP based on the business strategies and at the same time meet the Agency' technology objectives, investment and priorities for the next five to ten years. 


\subsection{The development process and methodology adopted for the ISSP}

The development of an ISSP was initiated in May 2005 and the core team for the project was established, comprising of private consultants, technology architects from the Agency's architecture and standards team, and communications experts. The team focused on the objectives and principles of the project by presenting a technology strategy that was aimed at closely aligning with the business strategies of the organisation. The project organisational structure was defined and governance for the project was provided by the Agency's information management and technology governance committee (Figure 1). An independent quality assurance was also appointed to carry out the necessary reviews at key times during the project lifecycle. A 'terms of reference' defined the establishment of subject matter expert groups that included project working groups and reference groups that provided the necessary expertise across a wide range of subjects including technology, sector strategy, government strategy, business strategy, and the Agency's core business processes.

Figure 1 ISSP governance and management model

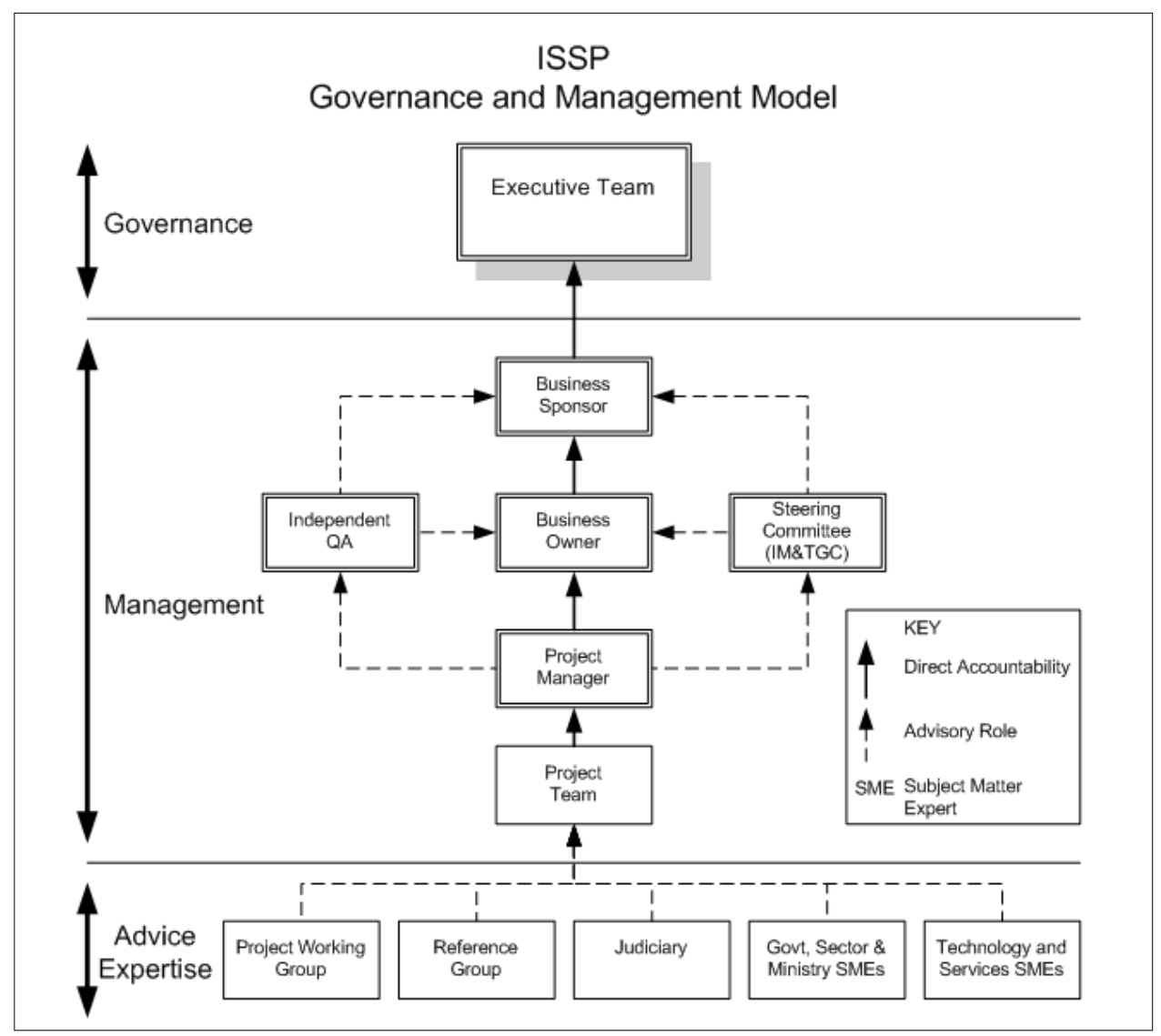


The development process of the ISSP adopted a formal management and governance model by answering the following three questions:

1 Where are we now?

2 Where do we want to be?

3 How do we get there?

The formal management and governance model was aimed adopting a detailed planning, good communications and formal project management practices and controls throughout the project lifecycle.

The methodology adopted for the ISSP was aimed to be flexible enough so that it could be used across most of the government agencies that wished to undertake a similar exercise (Figure 2). Initially, the deliverables from the development process of the ISSP were, the detailed project plan and the communications plan. While the project plan detailed the resources, activities and schedules along with key milestones within a timeframe, the communications plan identified the key stakeholder groups or individuals for which consultations and the necessary communications had to be considered. In addition to the stakeholder groups, direct consultation was determined for direct reports to the Agency's General Managers, with approval being required from the Agency's information management and technology governance committee. Finally, a group of interested central government agencies and external groups including IT industries were identified, for which communication strategies were developed.

Figure 2 Development methodology of the ISSP (see online version for colours)

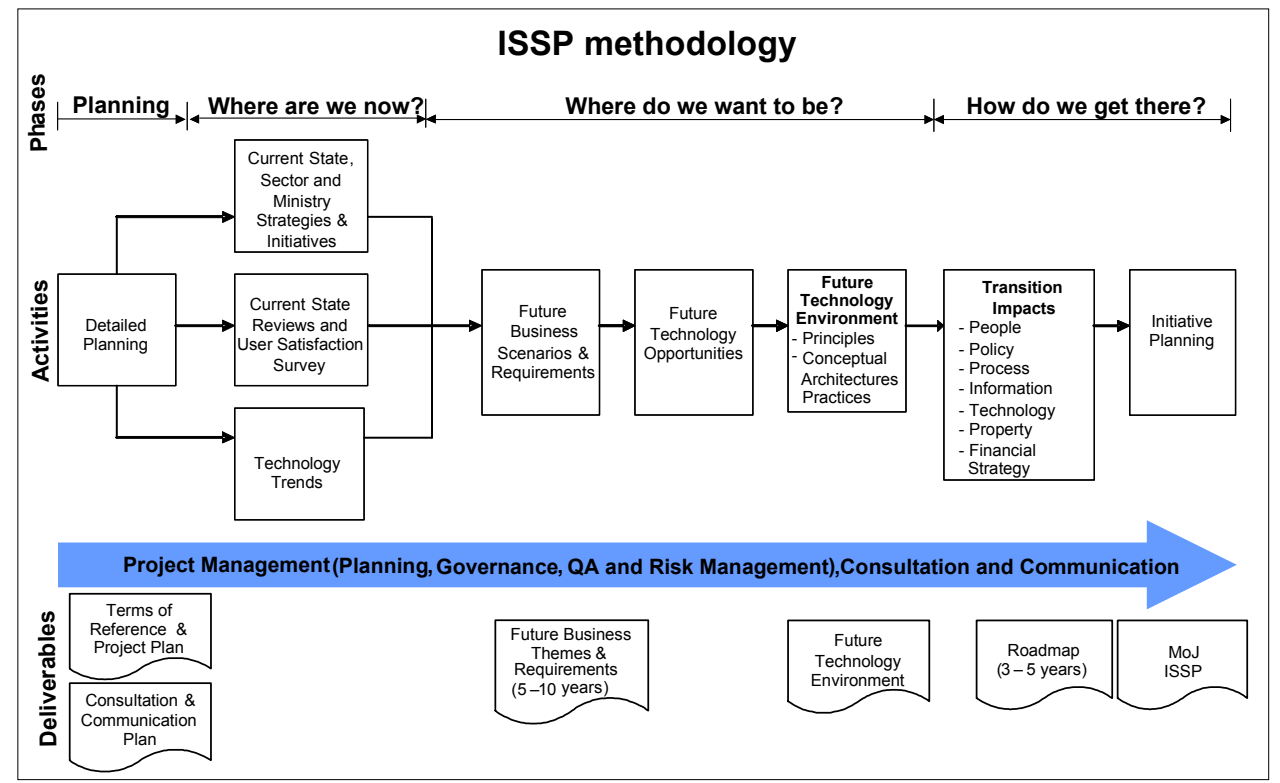


Once the initial planning and communications strategies were in place, the project team commenced work and was operating to understand the future business and technology environments. One of the challenges facing the project team was with respect to translating the Agency's business strategies into technology strategy. The team subsequently used the four key themes from the Agency's business strategy, namely:

1 putting service first

- $\quad$ service ethic, single view users, accessibility, enhanced awareness and consistent service

2 ensuring simple connected processes

- $\quad$ transaction management, streamlined processes and complex processes

3 building knowledge and expertise

- $\quad$ performance management, high capability, secured assets, shared knowledge, strategy/policy management and flexible and agile

4 enhancing agency integration

- agency roles and collaboration.

Figure 3 illustrates how the team had used the abovementioned 16 key themes from the Agency's business strategy to propose links with the future technology opportunities. While developing the technology opportunities and requirements, the core project team was aware of the need to include e-government initiatives within the thinking that went into the development of the Agency's ISSP.

Figure 3 Proposed alignment of business strategy with technology opportunities

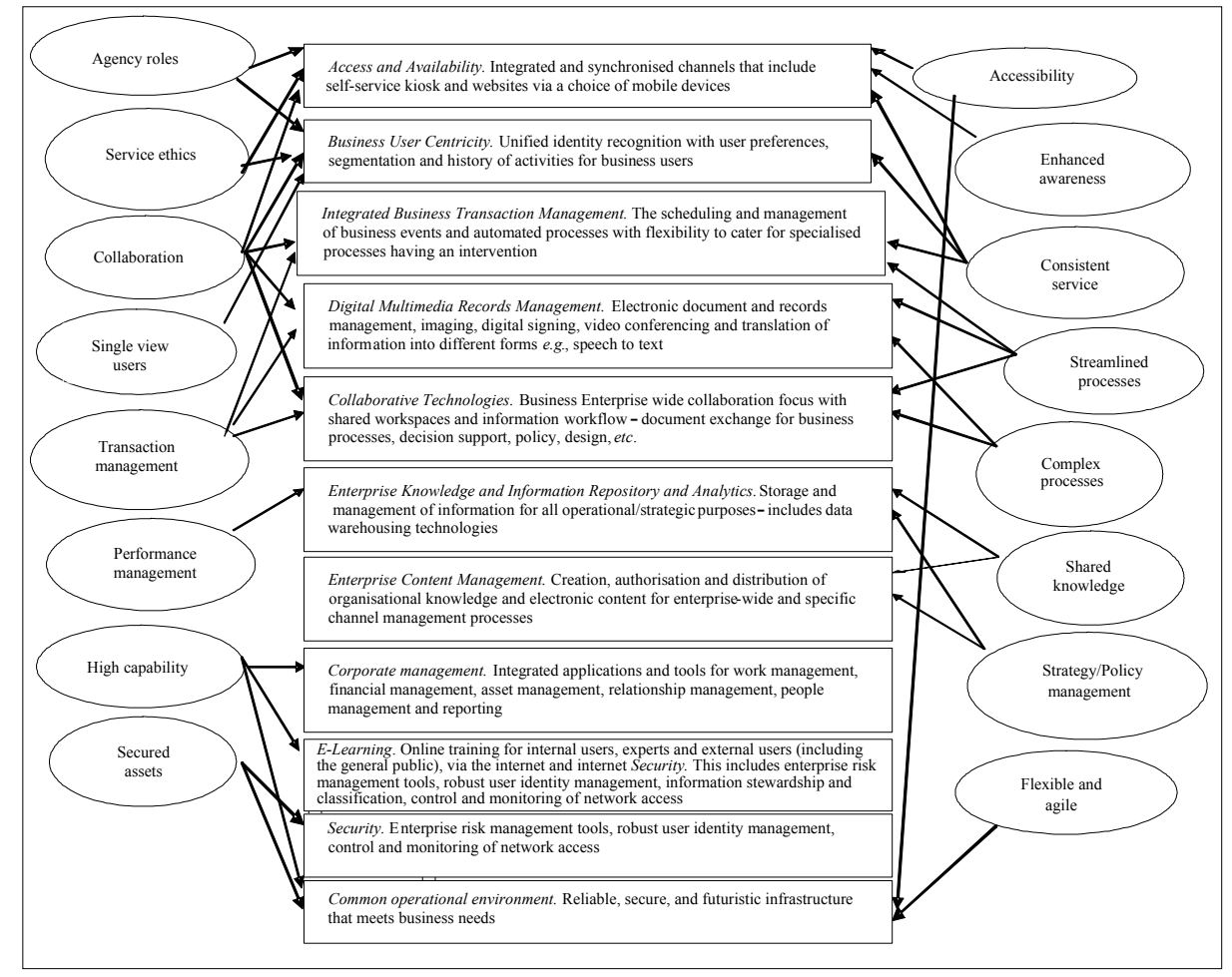


The project team developed a conceptual architecture using the technology strategies and principles as the guide from which to define the Agency's desired future IT environment. The conceptual architecture comprised of four diagrams which included an overview/summary architecture that demonstrated some of the future business scenarios, business architecture, an information model, and infrastructure architecture. The conceptual architecture diagrams were developed to convey the key messages to the technology architects that the ISSP should be developed with a business focus. These became the inputs to the development of an enterprise architecture that defined the technical details of the ISSP implementation. A roadmap was developed as a guide or work programme for the 2006/2007 financial year towards delivering the desired future technology environment. The steering committee adopted the roadmap approach to sequence the project initiatives using certain priority criteria that were ranked and assessed at the end of each phase of the ISSP implementation.

Though we were given the necessary access to all the design documents and reports of the Agency's ISSP, due to the sensitivity of the data, some of the design architectures could not be illustrated here. However, information collected from these sources and the feedback received from the project team members served as the basis for the case study investigation described in the next section.

\section{Case study analysis}

The methodology adopted for the development of the ISSP for the Agency was not based on a particular academic or industry model or framework but was based on good business planning practices. Hence, we examined the development process of the ISSP with the literature survey conducted on IS theoretical frameworks. We observe that the Agency's ISSP has similarities with the framework proposed by Mentzas (1997), which presents an ISSP process that adopts the elements of corporate strategy literature. Mentzas's approach specifies the use of five phases: strategic awareness, situation analysis, strategy conception, strategy formulation, and strategy implementation planning. The approach calls for the explicit involvement of top management in the ISSP development process, supports a teamwork approach, and calls for clear review and approval procedures in order to guarantee a quality outcome from the ISSP process whilst Mentzas purports the use of this methodology in order to achieve a high degree of alignment between business and IT strategy, he also emphasises that a degree of flexibility must be applied to the method that recognises the culture and current state of the organisation. Hence, we considered Mentzas' framework as the theoretical basis of the case study analysis.

We analysed the Agency's ISSP methodology using qualitative-survey techniques and subjective reviews of the case. Information was gathered from interviews that comprised of up to 24 semi-structured questions that were primarily open-ended questions with some quantitative ratings on a scale of 1 to 5 ( 1 for 'Failure', 2 for 'Significant improvements needed', 3 for 'Marginally successful', 4 for 'Successful but improvement can be made' and 5 for 'Highly successful'). The interviewees included business owner, project sponsor, key members of the Ministry's IT team, and project team members. Through the survey, we explored the following main aspects:

- the overall success of the ISSP

- the success of the ISSP development process and methodology 
- the alignment of the ISSP with the business strategies and objectives

- the alignment of the ISSP with e-government initiatives.

From the qualitative analysis undertaken from the survey feedback, we observe that the ISSP methodology adopted was, in general, successful but with some room for improvements. The survey conducted on the effectiveness of the ISSP development methodology indicate that $14 \%$ of the interviewees rated the level of success as 'marginally successful', 57\% consider it to be 'successful but improvements could be made', while $29 \%$ confirmed it be 'highly successful'. However, the $14 \%$ of the respondents quite critical about the ISSP methodology adopted attributed the success to an effective implementation. Hence, the overall feedback received from this study was that $71 \%$ of the participants perceived the ISSP implementation as 'successful but improvements could be made' and $29 \%$ of the respondents considered it to be 'highly successful'. This measure of success was further confirmed by the government's independent analysis conducted subsequently on the development process of the Agency's ISSP. From these findings, we conclude that the ISSP was quite successful in meeting its objectives in the implementation phase. However, improvements in the ISSP methodology could be incorporated by adopting a continuous review throughout the development process. As indicated by a participant, 'it is more worthwhile to conduct a gap analysis at each stage of the development process so as to revisit the relevant parts of current state in detail and this could help in re-shaping the initiatives within the roadmap'.

Next, we analysed the alignment of ISSP objectives with the business strategies. Here, the success rating arrived was about $57 \%$ of the participants regarding it to be 'successful but improvements could be made', while $43 \%$ of them agreeing the alignment to be 'highly successful'. The high success rating was attributed to the effective communications that were put in place. The workshops organised had helped the business representatives to develop a more detailed view of the IS requirements and the technology and services team to gain a better understanding of the business needs, issues and challenges. As one participant explains, 'these workshop sessions certainly helped me and the rest of the technology teams, to gain a better insight into the business'. However, improvements could be made by providing suitable resources for organising formal consultations. One participant views, 'the work area probably was not conducive as there is a lack of meeting rooms and break out areas for the team to organise consultations with the subject area experts. We had to use external facilities several times for team meetings and sessions.' Another area of improvement is to look beyond the review period by developing future business scenarios. One participant explains 'whilst the Agency's business strategy is based on a five year horison, it is necessary for the ISSP process to look further into the future, at a five to ten year horison, in order to consider the significant impact of the level of change required in order to develop and implement the technology required for supporting the future business needs'.

Finally, we analysed the alignment between ISSP objectives and the e-government strategies. Alignment with e-government initiatives was regarded by the interviewees as the least successful of the outcomes with $72 \%$ of the interviewees rating it as "marginally successful', and the remaining $28 \%$ rating the outcome 'successful but improvements could be made'. Many participants feel that the communication of e-government strategies should move from 'top to bottom'. One participant explains this further, 'whilst we recognise that external strategies such as the e-government initiatives are important, it 
was not the driving force behind our ISSP. We needed to get our own house in order with respect to establishing the foundations of our future IT systems before considering broader sector collaboration and joined-up government initiatives'.

From the case study analysis conducted, we identify the following success factors that had played a major role in the development process of the Agency's ISSP:

- Gaining top management support was a key success factor in the ISSP process.

- The use of a formal ISSP development methodology formed the backbone of the ISSP project development.

- Getting the terms of reference right was considered a key factor for commencing the ISSP development process successfully. However, improvements could be made here using a continuous review approach.

- Effective communications and consultations formed the major building blocks in the ISSP development process; however, there is room for improvements.

- The technology architects were encouraged throughout the ISSP development process to present content in a business-oriented format rather than technology-based.

- Developing future business scenarios as a mechanism for presenting the future view of how the Agency would operate was a key success factor in effectively formulating the Agency's business strategies and translating them into tangible business requirements upon which the technology requirements could be developed.

- E-government strategies were a key input into the ISSP development process. However, they should be given much more consideration for achieving tighter links with other government agencies.

\section{Recommendations}

Based on the findings of the case study, we propose a set of recommendations. We present these recommendations as a ten-point framework derived from the analysis of the Agency's ISSP process. We believe that this framework provides an effective guideline that could help in improving the effectiveness of the ISSP development process and the quality of the ISSP. The framework also places emphasis on improving the level of alignment with e-government initiatives so as to integrate these initiatives with the business objectives of each individual agency's ISSP. The ten-point proposed framework is given below:

1 Adopt a top-level IS strategy. The ISSP is not a technical document and it should not get bogged down by the technology vagaries. The ISSP is rather an important tool in gaining management consensus on the technology direction and understanding within the business about the future technology environment and what it takes to get there.

2 Adopt a flexible ISSP development methodology. Keep the ISSP methodology simple, flexible, and sign off deliverables as you go from one stage to the next. The methodology used to develop the Agency's ISSP has delivered a successful 
outcome for a significant state sector organisation. However a continuous review would help in fine-tuning the roadmap as the development process goes through one stage to the next.

3 Allocate resources for expert consultations. The case study of the Agency's ISSP shows clearly the benefits of employing external consultants who have prior experiences with regard to developing ISSPs. Appropriate resources should be allocated to organise formal consultations with these subject matter experts.

4 Think beyond the business review period. Translating the business strategies into operational strategies determine the supporting strategies (such as IT, HR, Finance, etc.) required for the future review period. This would significantly impact the business operations leading to a change. In order to develop and implement a sustainable IT infrastructure, think beyond the review period and develop future business scenarios.

5 Develop a map of business strategies with technology opportunities. Develop core themes as business strategies that would get implemented using the technology opportunities as these would determine the future technology environment of the organisation. Such a mapping process would lead to a good alignment of the technology strategies with the organisation's business strategies.

6 Ensure senior management support. An ISSP is a significant and costly investment and it requires support from the highest levels in the organisation in order to gain access to the resources needed for undertaking the work.

7 Adopt a formal communication mechanism. It is important to identify the stakeholders and put in place a communications strategy that ensures that the right messages are communicated to the right people, in the right way, at the right time. Good communications are also critical within the core project team as well as with the external stakeholders.

8 Prepare a 'terms of reference' and a roadmap. The terms of reference should be the first document to be prepared during the development process of the ISSP. This is to enable a consensus on the key principles and initiatives that underpin the project objectives. Similarly, a roadmap would serve as a compass for a successful implementation of the ISSP.

9 Ensure an awareness of e-government initiatives. It pays well if the project team, as well as the wider project groups and stakeholders have a clear awareness and understanding of the government's e-government strategies, initiatives and standards. It is important to encourage participants in the ISSP development process to think about how they can utilise e-government for the benefit of the organisation. This may require involvement with the State Services Commission's e-government subject matter experts.

10 Map the core themes of the e-government strategy with the organisation's business and IT strategies. While preparing the ISSP, the government agency should clearly show linkages between e-government strategy and their 
individual business and IT strategies. By establishing more linkages, the alignment with the e-government initiatives gets strengthened, leading to a better quality service under the umbrella of the government.

\section{Conclusions}

This research work explored the development process of an ISSP that wishes to tap on ICT for gaining business excellence. We considered a government state sector organisation and studied the influence of its business strategies and e-government strategies on the development of its ISSP. This case study revealed that the success in the development of an ISSP lies on various factors such as, ISSP development methodology adopted, communication strategies undertaken and the level of business alignment incorporated with e-government initiatives.

We critically analysed the development process of the ISSP of the case study and identified its success factors as well as improvement areas. We proposed a ten-point framework that provides a guideline for organisations embarking on ISSP under the e-government initiative. In particular, the framework is designed to enable state sector organisations to improve the effectiveness of their ISSP development process, to enhance the quality of their ISSP, and to incorporate a high level of ISSP alignment with e-government strategies. We believe that this study would lead to other similar studies and would benefit state sector organisations of the government planning to develop their own ISSPs.

As an extension of the research undertaken, possible future research work would be to investigate the ISSP development within several government agencies to ascertain if they concur with the findings from this single organisation case study. Further research could also be conducted to review whether the ten-point framework proposed in this paper improves the success of ISSP development initiatives within other government agencies with the aim of improving the level of alignment among business strategy, IT strategy and e-government strategy.

\section{Acknowledgements}

The authors are grateful to the project team of the case study for sharing their experiences with regard to the development process of ISSP, which served as valuable inputs to the case study analysis. The authors wish to thank both the internal and external members of the agency for their participation in the survey. Finally, the valuable comments from the reviewers of this paper are very much appreciated.

\section{References}

Andersen, K.V. (2006) 'E-government: five key challenges for management', The Electronic Journal of e-Government, Vol. 4, No. 1, pp.1-8.

Ang, J.S.K. and Teo, T.S.H. (2001) 'An examination of major IS planning problems', International Journal of Information Management, Vol. 21, No. 6, pp.457-470. 
As-Saber, S., Srivastava, A. and Hossain, K. (2006) 'Information technology law and e-government: a developing country perspective', Journal of Administration and Governance, Vol. 1, No. 1, pp.84-101.

Basu, S. (2004) 'E-government and developing countries: An overview', International Review of Law Computers and Technology, Vol. 18, No. 1, pp.109-132.

Byrd, T.A., Sambamurthy, V. and Zmud, R.W. (1995) 'An examination of IT planning in a large, diversified public organization', Decision Sciences, Vol. 26, No. 1, pp.49-73.

Chan, Y.E. and Huff, S.L. (1993) 'Strategic information systems alignment', Business Quarterly, Vol. 58, No. 1, pp.51-55.

Chan, Y.E., Sabherwal, R. and Thatcher, J.B. (2006) 'Antecedents and outcomes of strategic IS alignment: an empirical investigation', IEEE Transactions on Engineering Management, Vol. 53, No. 1, pp.27-47.

De, R. (2005) 'E-government systems in developing countries: stakeholders and conflict', Proceedings of Electronic Government, 4th International Conference, Copenhagen, pp.26-37.

Dillon, S., Deakins, E. and Chen, W.C. (2006) 'E-local government in New Zealand: the shifting policymaker view', The Electronic Journal of e-Government, Vol. 4, No. 1, pp.9-18.

Earl, M.J. (1993) 'Experiences in strategic information systems planning', MIS Quarterly, Vol. 17, No. 1, pp.1-24.

European Commission (2004) 'Reorganisation of government back offices for better electronic public services - European good practices (Back-office reorganization)', Final Report to the European Commission.

Germanakos, P., Christodoulou, E. and Samaras, G. (2006) 'Towards the definition of an e-government benchmarking status methodology', Proceedings of the 6th European Conference on e-Government (ECEG 2006), Philipps-Universitat Marburg, Germany, pp.179-188.

Gichoya, D. (2005) 'Factors affecting the successful implementation of ICT projects in government', The Electronic Journal of e-Government, Vol. 3, No. 4, pp.175-184.

Griffin, D. and Halpin, E. (2005) 'An exploratory evaluation of UK local e-government from an accountability perspective', The Electronic Journal of e-Government, Vol. 3, No. 1, pp.13-28.

Henderson, J.C. and Venkatraman, N. (1993) 'Strategic alignment: leveraging information technology for transforming organizations', IBM Systems Journal, Vol. 32, No. 1, pp.4-16.

Kaylor, C., Deshazo, R. and Van Eck, D. (2001) 'Gauging e-Government: a report on implementing services among American cities', Government Information Quarterly, Vol. 18, pp.293-307.

Ke, W. and Kee, W.K. (2004) 'Successful e-government in Singapore', Communications of the $A C M$, Vol. 47, No. 6, pp.95-99.

Krishna, S. and Walsham, G. (2005) 'Implementing public information systems in developing countries: learning from a success story', Information Technology for Development, Vol. 11, No. 2, pp.1-18.

Lederer, A.L. and Sethi, V. (1996) 'Key prescriptions for strategic information systems planning', Journal of Management Information Systems, Vol. 13, No. 3, pp.35-62.

Lee, T-R., Wu, H-C., Lin, C-J. and Wang, H-T. (2008) 'Agricultural e-government in China, Korea, Taiwan and the USA', Electronic Government, Vol. 5, No. 1, pp.63-70.

Mentzas, G. (1997) 'Implementing an IS strategy - a team approach, long range planning', Long Range Planning, Vol. 30, No. 1, pp.84-95.

Millar, L. (2004) 'Networking government: e-government in New Zealand', Public Sector Journal, Vol. 27, No. 4, pp.1-10.

NZSSC (2003) 'New Zealand e-government strategy', New Zealand State Service Commission Report, Wellington: Government Printing Office.

Obi, T. (2007) '2007 Waseda University e-government ranking', egovblog - The Future of Governments, Tokyo Press Release, pp.1-9. 
Poelmans, M. (2006) 'The e-citizen charter as an instrument to boost e-government', in P. Cunningham and M. Cunningham (Eds.) Exploiting the Knowledge Economy: Issues, Applications, Case Studies, Amsterdam: IOS Press.

Poelmans, M. (2007) 'Reinventing public service delivery by implementing the e-citizen charter', in P. Cunningham and M. Cunningham (Eds.) Expanding the Knowledge Economy: Issues, Applications, Case Studies, Amsterdam: IOS Press.

Schware, R. and Sudan, R. (2005) 'E-development: from excitement to effectiveness', The World Summit on the Information Society, pp.79-99.

Siau, K. and Long, Y. (2005) 'Synthesising e-government stage models - meta-synthesis based on a meta-ethnography approach', Industrial Management and Data Systems, Vol. 105, No. 4, pp.443-458.

Tallon, P.P. (2008) 'A process-oriented perspective on the alignment of information technology and business strategy', Journal of MIS, Vol. 24, No. 3, pp.231-272.

Teubner, R.A. (2007) 'Strategic information systems planning: a case study from the financial services industry', Journal of Strategic Information Systems, Vol. 16, No. 1, pp.105-125.

Wang, Y., Pan, H. and Li, T. (2007) 'The data mining of the e-government on the basis on fuzzy logic', IEEE International Conference on Information Technology, Vols. 20-24, pp.774-777.

Wimmer, M.A., Codagnone, C. and Ma, X. (2007) 'Developing an e-government research roadmap: method and example from eGovRTD2020', in M.A. Wimmer, H.J. Scholl and A. Grönlund (Eds.) Electronic Government. Proceedings of EGOV 07, LNCS \# 4656, Berlin: Springer Verlag, pp.1-12. 